\title{
Site-specific Variations in RNA Folding Thermodynamics Visualized by 2-Aminopurine Fluorescence ${ }^{\dagger}$
}

\author{
Jeff D. Ballin $¥$, Shashank Bharill 9 , Elizabeth $\mathrm{J}_{*}$ Fialcowitz-White $\ddagger$, Ignacy Gryczynski§, \\ Zygmunt Gryczynski ${ }^{\mathbb{I}}$, and Gerald M. Wilson $\ddagger^{*}$ \\ Department of Biochemistry and Molecular Biology and Marlene and Stewart Greenebaum Cancer \\ Center, University of Maryland School of Medicine, Baltimore, Maryland 21201, Department of \\ Molecular Biology and Immunology, Health Science Center, University of North Texas, Fort Worth, \\ Texas 76107, and Department of Cell Biology, Health Science Center, University of North Texas, \\ Fort Worth, Texas 76107
}

\begin{abstract}
The fluorescent base analogue 2-aminopurine (2-AP) is commonly used to study specific conformational and protein-binding events involving nucleic acids. Here, combinations of steadystate and time-resolved fluorescence spectroscopy of 2-AP were employed to monitor conformational transitions within a model hairpin RNA from diverse structural perspectives. RNA substrates adopting stable, unambiguous secondary structures were labeled with 2-AP at an unpaired base, within the loop, or inside the base-paired stem. Steady-state fluorescence was monitored as the RNA hairpins were transitioned between folded and unfolded conformations using thermal denaturation, urea titration, and cation-mediated folding. Unstructured control RNA substrates permitted the effects of higher-order RNA structures on 2-AP fluorescence to be distinguished from stimulusdependent changes in intrinsic 2-AP photophysics and/or interactions with adjacent residues. Thermodynamic parameters describing local conformational changes were thus resolved from multiple perspectives within the model RNA hairpin. These data provided energetic bases for construction of folding mechanisms, which varied among different folding/unfolding stimuli. Timeresolved fluorescence studies further revealed that 2-AP exhibits characteristic signatures of component fluorescence lifetimes and respective fractional contributions in different RNA structural contexts. Together, these studies demonstrate localized conformational events contributing to RNA folding and unfolding that could not be observed by approaches monitoring only global structural transitions.
\end{abstract}

Fluorescence spectroscopy of 2-aminopurine (2-AP) has played a pivotal role in the elucidation of interactions within and between nucleic acids and other biomolecules including proteins, nucleic acids, and larger structures such as multicomponent ribonucleoprotein complexes. The use of 2-AP in fluorescence studies is attractive because it can form Watson-Crick type base pairs with either thymidine (DNA), uracil (RNA), or cytosine (RNA and DNA), has a red-

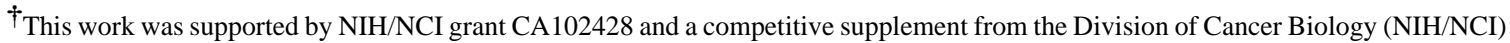
under the Activities to Promote Research Collaborations initiative (to G.M.W.). Additional support (for S.B.) was provided by Public Health Service grant P20 MD001633.

*To whom correspondence should be addressed: Department of Biochemistry and Molecular Biology, University of Maryland School of Medicine, 108 N. Greene St., Baltimore, MD 21201. Telephone: (410)706-8904. Fax: (410)706-8297. e-mail: gwils001@umaryland.edu.

University of Maryland School of Medicine.

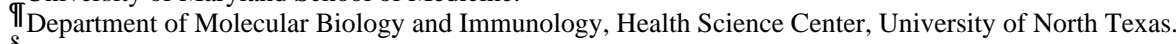

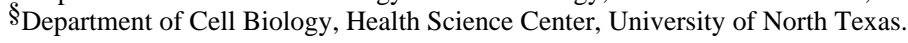

SUPPORTING INFORMATION Data from additional control experiments referenced in the text are contained within Supplementary figures S1-S5 and their associated legends, and Supplementary Table S1. This material is available free of charge via the Internet at http://pubs.acs.org.
} 
shifted absorption spectrum allowing differential excitation in the presence of nucleic acids and proteins, and because its fluorescence is strongly quenched by base stacking interactions (1-3). The fluorescence properties of 2-AP are extremely sensitive to local changes in conformation, making this base analogue nearly ideal for studies involving structural dynamics (4-7), mismatch $(8,9)$ or abasic $(10-12)$ sites, base flipping $(2,13,14)$, and protein-nucleic acid association (15-18). Examples include characterization of ribozyme folding (19-21) and catalysis $(22,23)$, riboswitches $(24)$, interactions with polymerases (25-27), and nucleic aciddrug interactions (28-31). However, the use of fluorescent base analogue probes such as 2-AP also permits localized conformational events to be discriminated from more global structural phenomena. This is in stark contrast to methodologies such as UV/Vis spectroscopy and circular dichroism, which monitor all components in solution as an ensemble. While other techniques with this capacity for localized monitoring do exist (eg: NMR, gel electrophoresis of kinetically-trapped radiolabeled products), these approaches are much more complicated and time consuming. Furthermore, the reaction time scales experimentally accessible to such strategies are limited.

To promote more sophisticated analyses of 2-AP spectroscopic data, numerous model systems have been characterized to assess positional effects (32), sequence dependence (33-35), stacking dynamics $(5,36-38)$, and fluorescence quenching $(34,38,39)$. In general, positioning a 2-AP residue near the interior of duplex DNA strongly increases energy transfer efficiency and spectral shifts. Adenines adjacent to 2-AP can act as "antennae", transferring absorbed energy to the fluorophore (35). All bases exhibit the ability to statically and dynamically quench 2-AP to similar extents, however, base pairing and hydrogen bonding are not generally considered to significantly influence 2-AP fluorescence $(40,41)$. Computational modeling $(37,41-43)$ and experimental studies of idealized systems $(4,44-46)$ have explored the nature of quenching mechanisms for 2-AP fluorescence. In general, 2-AP fluoresces as a consequence of photon emission from the $\pi \pi^{*}$ singlet state, while nonradiative processes diminish quantum yield from this excited state $(41,42)$. The conformational motion of stacked bases is crucial to quenching mechanisms. For example, the emission intensity of 2-AP in duplex DNA increases dramatically upon cooling and eventually becomes comparable to free 2-AP at low temperatures (38). However, while many studies have employed 2-AP as a local sensor of specific DNA structures, relatively few have examined its utility in the context of RNA dynamics $(6,36)$, and reported examples typically involve very dramatic RNA conformational events $(7,19,22,47)$. RNA exhibits significantly more structural diversity under physiological conditions than analogous DNA sequences $(48,49)$. Accordingly, correlation of fluorescence changes in specifically localized 2-AP residues to RNA structural dynamics could significantly contribute to the robust elucidation of many ribonucleic interactions. In particular, how do the fluorescence properties of 2-AP respond to changes in local RNA structure? What RNA conformational events can be monitored through changes in 2-AP fluorescence? What can time-resolved fluorescence studies and the resolution of component lifetimes reveal about local RNA structural contexts?

This study explores the effects of RNA conformational changes on the fluorescence properties of 2-AP in diverse RNA structural environments. We compared the steady-state and timeresolved fluorescence of 2-AP in three positions of a stable RNA hairpin with unambiguous structure: at an unpaired base within the stem, at the top of the loop, and in a stacked position near the base of the stem. Changes in fluorescence emission were measured as a function of RNA hairpin folding, and demonstrate its utility in monitoring the extent and nature of RNA conformational changes. Studies of 2-AP-labeled control RNA variants incapable of folding were used to separate changes in intrinsic 2-AP photophysics and/or random nearest neighbor base stacking interactions from the effects of specific higher-order RNA structures on 2-AP fluorescence. Our results further demonstrate that the use of unstructured controls as a basis for comparison not only allows more sophisticated interpretation of 2-AP fluorescence data, 
but that neglecting these controls can preclude quantitative characterization of the processes of interest.

\section{EXPERIMENTAL PROCEDURES}

\section{Materials}

For all experiments, solutions were buffered with potassium HEPES (Sigma) titrated to $\mathrm{pH} 7.4$ using concentrated acetic acid (American Bioanalytical) or with HEPES free acid, titrated to pH 7.4 using sodium hydroxide. Potassium acetate and magnesium acetate (Mallinckrodt) served as additional sources of monovalent and divalent cations, respectively.

\section{Synthetic RNA oligonucleotides}

All RNA substrates were synthesized, 2'-hydroxyl deprotected, and purified by Dharmacon Research. RNA oligonucleotides were resuspended in ultrapurified water and quantified by $\mathrm{A}_{260}$ in $10 \mathrm{mM}$ potassium HEPES/acetic acid ( $\mathrm{pH}$ 7.4) and $9 \mathrm{M}$ urea, using extinction coefficients provided by Dharmacon. Extinction coefficients $\left(\varepsilon_{260}, \mathrm{~L} \cdot \mathrm{mol}{ }^{-1} \cdot \mathrm{cm}^{-1}\right)$ used were HP6, 233400; HP14, 237000; HP21, 232200; C6, 68700; C14, 87700; C21, 68600. All RNA hairpin substrates (denoted HPXX) were of the sequence 5'-CAUACAC

GAAAGAAAUCGGUAUG-3', where the internal number $(X X)$ indicates the position of the single 2-AP base substitution for each oligo (Figure 1). Control RNA substrates were 8 nucleotides in length, with sequences equivalent to portions of the full length hairpin and containing 2-AP in the 6 position. Control RNAs are indicated as $\mathrm{C} X X$, where $X X$ indicates the corresponding 2-AP labeling position in the full length hairpin sequence. The structural integrity of the hairpin sequences was verified by denaturing polyacrylamide gel electrophoresis stained with SYBR Gold. No evidence of RNA degradation was observed, even under overloaded conditions (data not shown).

\section{Nuclease digestion studies}

Hairpin RNA substrates (HP6, HP14, HP21) were hybridized to a complementary DNA oligo 5'-( $\left.\mathrm{NH}_{2}\right)$-CATACCGATTTCTTTCGTG-3' (Integrated DNA Technologies) to generate an RNA:DNA duplex containing a 4-nucleotide 5'-overhang on the RNA strand. This step improved accessibility of the RNA 5'-hydroxyl moiety to permit radiolabeling with $\left[\gamma^{32} \mathrm{P}\right]$ ATP to specific activities of 3-5 $\times 10^{3} \mathrm{cpm} / \mathrm{fmol}$ using T4 polynucleotide kinase (Promega) as described (50). End-labeled RNA/DNA hybrids were treated with RQ1 RNase-free DNase (Promega), then purified by extraction with phenol:chloroform:isoamyl alcohol (25:24:1). Unincorporated radiolabel was removed using Sephadex G-25 Quick-Spin RNA purification columns (Roche) and RNA substrates purified from denaturing polyacrylamide gels as described (51). RNase digestion reactions were performed essentially as described (52), however, $5 \mathrm{mM} \mathrm{MgCl} 2$ was included in all reactions and the RNA hairpins were heated to 65 ${ }^{\circ} \mathrm{C}$ for 2 minutes followed by slow cooling (over $20-30$ minutes) to $30{ }^{\circ} \mathrm{C}$ before addition of RNase $\mathrm{T}_{1}$ (Sigma; 0.033 units/reaction) or RNase $\mathrm{T}_{2}$ (Sigma; $9 \times 10^{-5}$ units/reaction) and incubation at $25{ }^{\circ} \mathrm{C}$ for 5 minutes. Hydroxide-ion mediated cleavage was used to generate a single-base ladder of the ${ }^{32} \mathrm{P}-5^{\prime}-\mathrm{HP} 14$ substrate as described in protocols provided by Ambion. Reaction products were fractionated by electrophoresis through a denaturing $12 \%$ acrylamide gel. The gel was then dried and ${ }^{32} \mathrm{P}$-labeled RNA cleavage products visualized using a Phosphorimager (GE Biosciences).

\section{Steady-state fluorescence measurements}

All steady-state fluorescence experiments were performed using $1 \mathrm{~cm} \times 1 \mathrm{~cm}$ quartz cuvettes in a Cary Eclipse fluorometer (Varian) with $5 \mathrm{~nm}$ excitation and emission slits unless otherwise 
specified. Excitation was at $303 \mathrm{~nm}$. In cases where a single wavelength is monitored (eg: thermal melts), fluorescence emission was measured at $370 \mathrm{~nm}$.

\section{Thermal denaturation studies}

The thermodynamic stability of RNA folding was assessed by thermal denaturation of samples containing $0.3-3 \mu \mathrm{M}$ RNA, $10 \mathrm{mM}$ KHEPES/HOAc (pH 7.4) and either [i] $50 \mathrm{mM}$ KOAc and $5 \mathrm{mM} \mathrm{Mg}(\mathrm{OAc})_{2}$, or [ii] $4.5 \mathrm{M}$ urea with or without $5 \mathrm{mM} \mathrm{Mg}(\mathrm{OAc})_{2}$. Cuvettes were equilibrated at $12{ }^{\circ} \mathrm{C}$ for 10 minutes before initiating a $1{ }^{\circ} \mathrm{C} /$ minute temperature gradient to 85 ${ }^{\circ} \mathrm{C}$, recording 2-AP fluorescence $(370 \mathrm{~nm})$ at $0.5^{\circ} \mathrm{C}$ intervals using a Cary Eclipse fluorometer equipped with a Peltier temperature controller and in-cell temperature probe. The apparent melting temperature $\left(T_{m}\right)$ for each of the hairpins (HP6, HP14, HP21) was determined as the extremum of the derivative of fluorescence with respect to temperature following ratiometric correction to fluorescence from control RNA substrates (C6, C14, and C21, respectively) at each temperature.

\section{Thermodynamic estimation of RNA folding transitions}

The thermodynamic stability of hairpin RNA folding was also examined by chemical denaturation using urea. Fluorescence $(370 \mathrm{~nm})$ of 2-AP-labeled RNA samples $(300 \mathrm{nM})$ was measured at $25^{\circ} \mathrm{C}$ in $10 \mathrm{mM} \mathrm{KHEPES} / \mathrm{HOAc}(\mathrm{pH} \mathrm{7.4})$ as a function of urea concentration. Conformation-dependent changes in RNA hairpin substrate fluorescence were resolved from other effects by taking the ratio of fluorescence from hairpin versus the corresponding unstructured control sequences at each urea concentration, yielding $F_{H P: C}$ ratio. Hairpin RNA denaturation was considered as a two-state, urea-dependent transition between native and unfolded conformations yielding asymptotic hairpin:control fluorescence ratios $F_{\text {native }}$ and $F_{\text {unfolded }}$, respectively. Asymptotic fluorescence ratios and thermodynamic parameters describing denaturant-induced hairpin unfolding transitions were estimated from the change in $F_{H P: C}$ ratio as a function of urea concentration using equations 1 and 2 adapted from the linear extrapolation method of Santoro and Bolen (53), as modified by Manyusa and Whitford (54):

$$
F_{H P: C} \quad \text { ratio }=F_{\text {native }}-\left\lceil\frac{\left(F_{\text {native }}-F_{\text {unfolded }}\right) \cdot e^{-\Delta G_{\mathrm{u}} / R T}}{1+e^{-\Delta G_{\mathrm{u}} / R T}}\right\rceil
$$

where

$$
\Delta G_{\mathrm{u}}=\Delta G_{\mathrm{uw}}-m_{\mathrm{eq}}[\mathrm{urea}]
$$

Here, $\Delta G_{\mathrm{u}}$ represents the free energy of hairpin denaturation at each concentration of urea.

$\Delta G_{\mathrm{uw}}$ is the free energy of RNA unfolding in the absence of denaturant, while $m_{\mathrm{eq}}$ relates its sensitivity to urea concentration. All parameters were resolved from $F_{H P: C \text { ratio }}$ versus [urea] plots by nonlinear regression using PRISM v3.0 (GraphPad) with $R=1.987 \times 10^{-3}$ $\mathrm{kcal} \cdot \mathrm{mol}^{-1} \cdot \mathrm{K}^{-1}$.

$\mathrm{Mg}^{2+}$-dependent RNA conformational transitions were resolved by nonlinear regression of $F$ versus $\left[\mathrm{Mg}^{2+}\right]$ plots using a cooperative binding model:

$$
F=F_{0}+\left(F_{f}-F_{0}\right) \times\left[\frac{\left(\frac{\left[\mathrm{Mg}^{2+}\right]}{\left[\mathrm{Mg}^{2+}\right]_{1 / 2}}\right)^{h}}{1+\left(\frac{\left[\mathrm{Mg}^{2+}\right]}{\left[\mathrm{Mg}^{2+}\right]_{1 / 2}}\right)^{h}}\right]
$$

where $F_{0}$ and $F_{f}$ are the initial and final fluorescence intensities, respectively, for a given transition, $\left[\mathrm{Mg}^{2+}\right]_{1 / 2}$ is the magnesium ion concentration yielding half-maximal fluorescence change and $h$ is the Hill coefficient (55). For these experiments, ratiometric correction of hairpin 
fluorescence was not required since fluorescence from control substrates was minimally affected by the presence of $\mathrm{Mg}^{2+}$ (Results).

\section{Time-domain fluorescence measurements}

Time-domain measurements were performed on a FluoTime 200 (Picoquant) equipped with a Hamamatsu microchannel plate $(\mathrm{MCP})$ providing $<50$ ps resolution. The emission monochromator was set to $370 \mathrm{~nm}$, with the emission and excitation slits fully open, and polarizers set to magic angle conditions. The excitation source was a $295 \mathrm{~nm}$ LED driven at a $10 \mathrm{MHz}$ repetition rate by a PDL800 driver (Picoquant) fitted with a Corning 7-54 short pass filter for wavelengths below $320 \mathrm{~nm}$. The emission side was equipped with a $365 \mathrm{~nm}$ long pass filter in front of the monochromator. Time-resolved fluorescence data were analyzed using the Fluofit software package (Picoquant). Lifetime data were fit using nonlinear least squares analysis to a sum of $n$ exponentials

$$
I(t)=\sum_{i=1}^{n} \alpha_{i} e^{-\frac{t}{\tau_{i}}}
$$

where $\alpha_{i}$ is the fractional contribution of each component lifetime $\left(\tau_{i}\right)$. When more than one lifetime component is indicated, the amplitude weighted average lifetime is reported as

$$
\tau_{\mathrm{amp}}=\sum_{i=1}^{n} \alpha_{i} \tau_{i}
$$

\section{RESULTS}

\section{Design and structural validation of 2-AP labeled RNA substrates}

The 23-nucleotide RNA hairpin used in this study includes an 8-base pair stem interrupted by an unpaired base in the 6 position and capped with a 6-base loop (Figure 1B). 2-AP was substituted for adenine in one of three locations: the single unpaired base (HP6), in the loop (HP14), or within the stem (HP21). The 2-AP positions were chosen as archetypes of common local environments found in most structured RNA molecules. Individual unpaired bases are common in structured RNAs (56) and can be intercalated (57) or extrahelical (58-60) depending on sequence and structural context. 6-membered RNA loop structures such as those within the HIV-1 trans-activation response (TAR) element $(61,62)$ and the internal ribosome entry site of poliovirus (63) show significant local conformational dynamics and are essential for recognition of and association with trans-acting binding factors. Computational modeling of the model RNA sequence using mFold $(64,65)$ returned only one predicted structure, even when permitting 95\% suboptimality. Control sequences were designed to assist in the differentiation of nearest neighbor and/or intrinsic 2-AP photophysical effects versus secondary RNA structural effects on 2-AP fluorescence. Each control RNA substrate (C6, C14, and $\mathrm{C} 21$ ) was 8 nucleotides in length and identical in sequence to the corresponding subsections of the hairpin substrate (HP6, HP14, HP21) with the 2-AP substitution positioned three nucleotides from the 3' end. Nuclease digestion analysis (Figure 1C) of the HP6, HP14 and HP21 substrates indicates that each adopts a hairpin-like structure consistent with the mFold prediction. First, digestion of all three RNA substrates with RNase $T_{1}$ yielded a single significant cleavage event at position G12, the sole unpaired G residue within the hairpin structure. Second, all hairpin substrates exhibited enhanced sensitivity to RNase $\mathrm{T}_{2}$, which preferentially cleaves 3' of single stranded nucleotides, at positions 10-15 (Figure 1C, bracket), as expected for a loop region. Enhanced RNase $\mathrm{T}_{2}$ sensitivity was also observed at the 3' end, suggesting that some duplex breathing may be occurring on the time scale of the experiment. Nuclease sensitivities at all cleavage sites were consistent among the three hairpin substrates, indicating that the 2-AP substitutions do not significantly alter the structure of the folded product. Finally, the folding of all hairpin substrates displayed similar sensitivity to $\mathrm{Mg}^{2+}$ 
concentration when measured by UV hypochromicity, indicating that the position of 2-AP labeling does not significantly impact global folding thermodynamics (Supplemental Figure S1).

While the preceding data indicate a common RNA structure for each of the 2-AP-substituted RNA hairpins, fluorescence emission from 2-AP varied dramatically between the unpaired (HP6), loop (HP14), and base-paired (HP21) positions, consistent with the extreme sensitivity of 2-AP fluorescence to its local environment. While shifts in the wavelengths yielding maximal emission were small ( $1 \mathrm{~nm}$ or less), emission magnitudes varied strongly with the extent of folding and the identity of adjacent residues (Table 1 and Figure 2). For example, the hairpin RNA substrate containing 2-AP in place of the single unpaired adenosine (HP6) exhibited approximately 6-fold stronger fluorescence intensity versus its corresponding unstructured control sequence (C6). Presentation of 2-AP within the RNA loop also increased fluorescence emission but to a lesser extent (1.8-fold increase for HP14 versus C14). Enhanced emission from the loop-positioned 2-AP residue is consistent with previous studies indicating that 2-AP fluorescence increases with solvent exposure and minimization of base stacking (66). Similarly, the dramatic increase in 2-AP fluorescence from the HP6 versus C6 substrates supports an extrahelical or "bulged" conformation for the unpaired base at position 6 , rather than intercalation between stacked helices. In contrast, HP21 exhibited 22\% weaker fluorescence intensity than $\mathrm{C} 21$, indicating that emission from a stacked, base-paired 2-AP residue is slightly but measurably decreased relative to the corresponding unpaired base. To verify that local RNA structural environments were largely responsible for the differences in 2-AP emission between hairpin RNA substrates and their respective 8-nucleotide control sequences, fluorescence was also measured under denaturing conditions. The intensity of 2AP fluorescence was only modestly influenced by urea, decreasing $7.4 \pm 0.1 \%$ in $9 \mathrm{M}$ urea relative to native solution conditions (data not shown). In the presence of $9 \mathrm{M}$ urea, the fluorescence intensities of HP14 and HP21 were within 10-12\% of their corresponding control sequences, while the 6-fold difference in emission from the HP6 versus C6 substrates converged to approximately $25 \%$ (Table 1). Similarities in emission between paired hairpin and control RNA substrates under denaturing conditions indicates that adoption of RNA secondary structure is predominantly responsible for the unique variations in 2-AP fluorescence from each folded hairpin RNA relative to control sequences. As such, localization of 2-AP in different RNA structural contexts can impart distinct photophysical consequences on the fluorophore that may reveal characteristics of local RNA conformation independent of global RNA folding.

Comparing the fluorescence of control RNA substrates under native and denaturing conditions also revealed that nearest-neighbor RNA sequence effects can significantly contribute to net emission intensity. While C6 and C21 showed similar quantum yields under both native and denatured conditions (Table 1), emission from $\mathrm{C} 14$ was roughly double the fluorescence intensity from either C6 or C21, regardless of the solution conditions. Consistent with other studies (35), these data show that the fluorescence intensity of 2-AP flanked by adenine residues is enhanced relative to 2-AP flanked by pyrimidines independent of higher-order RNA structure, and furthermore, demonstrate that dramatic differences in fluorescence are possible simply by changing the labeling position within the RNA molecule. Nearest neighbor effects on 2-AP fluorescence and their implications for probe design are addressed further under Discussion.

\section{Modulation of 2-AP fluorescence by thermal denaturation of RNA substrates}

One goal of this study was to correlate changes in the fluorescence of 2-AP-substituted RNA substrates with defined structural transitions. Thermal denaturation approaches are commonly used to measure the stability of secondary and tertiary structural elements in RNA, which can 
be considered thermodynamically as a net sum of multiple local conformational changes. However, with appropriate controls, we reasoned that regio-selective 2-AP substitution could permit evaluation of local conformational events independent of global changes occurring during RNA structural transitions.

2-AP fluorescence was measured as a function of temperature for each of the hairpin RNA substrates and their cognate 8-mer control sequences. Comparing the temperature dependence of 2-AP emission between individual hairpin:control substrate pairs was expected to allow secondary structural effects to be discriminated from thermal effects on either the photophysics of 2-AP or interactions with flanking residues. Consistent with this hypothesis, the fluorescence intensities of each hairpin:control RNA pair converged at high temperatures as hairpin secondary structure was denatured (Figure 3A). All control substrates exhibited weaker emission with increasing temperature, although the magnitude of this decrease varied, suggesting that nearest neighbor effects impact the temperature dependence of 2-AP fluorescence emission (Figure S2). By contrast, the hairpin RNA substrates displayed more complex behavior consistent with relaxation of secondary structure (Figure 3A). Identical behavior was observed in replicate experiments across a titration of RNA substrate $(0.3-3$ $\mu \mathrm{M}$; Figure S3). The independence of this thermal transition with respect to RNA concentration verified that unfolding of these hairpin substrates is a unimolecular process (67).

To extract temperature-dependent fluorescence changes resulting specifically from the release of secondary structure, the fluorescence of each hairpin substrate was normalized to emission from its cognate control RNA at each measured temperature (Figure 3B). The apparent melting temperatures $\left(T_{m}\right)$ of RNA structural transitions were then estimated from derivative plots (Figure 3C). Following normalization to the unstructured control, a 2-AP residue inserted in the bulged position (HP6) displayed a dramatic decrease in fluorescence with increasing temperature, exhibiting a well defined melting transition at $56^{\circ} \mathrm{C}$. 2-AP residues inserted into loop (HP14) and stem (HP21) positions also revealed structural transitions near $57^{\circ} \mathrm{C}$ and 56 ${ }^{\circ} \mathrm{C}$, respectively, although the magnitude of change in fluorescence intensity accompanying these unfolding events was smaller than that observed from the HP6 substrate. The equivalent $T_{m}$ values determined for the hairpin RNA substrate from all 2-AP-labeled positions suggests that denaturation of this RNA is a two state process. It is noteworthy that the derivative plots for unfolding at the bulged (HP6) and loop (HP14) positions display local minima while at the stem position (HP21) a local maximum is indicated. This difference is consistent with the relative fluorescence quantum yield exhibited by 2-AP in each structural environment, since emission is enhanced in bulged and looped conformations relative to unstructured controls, while emission from base-paired 2-AP residues is decreased (Figure 2).

\section{Modulation of 2-AP fluorescence by chemical denaturation of RNA substrates}

Urea titrations present an alternative means to characterize the thermodynamics of nucleic acid folding (68). Here, this technique was used as an orthogonal approach to monitor local RNA structural events contributing to denaturation of 2-AP-substituted hairpin substrates. Similar to the thermal denaturation experiments (above), both hairpin and control RNA substrates exhibited significant changes in 2-AP fluorescence as a function of urea concentration (Figure 4A). Accordingly, 2-AP-substituted hairpin substrate fluorescence was normalized to emission from cognate control RNAs at each urea concentration to permit fluorescence changes resulting from secondary structural events to be discriminated from primary structural influences and/ or alterations in 2-AP photophysics. Plots of control-normalized hairpin substrate fluorescence versus urea concentration yielded saturable functions consistent with denaturant-dependent release of the folded conformation for each RNA hairpin (Figure 4B). Analyses of these data using a linear extrapolation model (equation 1 and equation 2) permitted the free energy of folding in the absence of denaturant $\left(\Delta G_{\mathrm{UW}}\right)$ and the sensitivity of folding energy to urea 
$\left(m_{\mathrm{eq}}\right)$ to be estimated (Table 2). $\Delta G_{\mathrm{UW}}$ was greatest for the HP14 substrate, indicating that local RNA conformation within the loop position is more stable than near the bulged base or within the stem region in the absence of denaturant. However, the free energy of folding within the loop region also displayed significantly greater sensitivity to urea (Table $2, c f . m_{\mathrm{eq}}$ values). Together, these data suggest that urea preferentially disorders the loop bases before release of base-paired structures within this model RNA substrate. Furthermore, these experiments demonstrate that the contribution of local events to global RNA stability can be monitored by use of specific 2-AP insertions compared to appropriate unstructured control RNAs.

\section{Modulation of 2-AP fluorescence by $\mathbf{M g}^{2+}$-stabilized folding of RNA substrates}

The stability of RNA folding is strongly coupled to cation concentrations. In particular, the contributions of $\mathrm{Mg}^{2+}$ to secondary and tertiary RNA structural transitions have been extensively characterized (20,69-72). To assess the utility of the 2-AP-substituted RNA hairpin model for evaluation of $\mathrm{Mg}^{2+}$-dependent changes in local RNA conformation, experimental conditions permitting cation-dependent modulation of RNA structure were required. The intrinsic melting temperatures of each RNA hairpin substrate $\left(\approx 56^{\circ} \mathrm{C}\right.$; Table 2$)$ indicated that the thermodynamic favorability of hairpin formation must be reduced to make this possible at ambient temperatures. Urea titration analyses indicated that each RNA hairpin substrate was at least $80 \%$ unfolded in $4.5 \mathrm{M}$ urea (Figure 4B). By thermal denaturation, unfolding transitions for all 2-AP-labeled positions within the hairpin substrate were observed near or below room temperature in $4.5 \mathrm{M}$ urea under hypotonic solution conditions, but were dramatically stabilized by addition of $5 \mathrm{mM} \mathrm{Mg}^{2+}$ (Figure S4, Table 2).

At $25{ }^{\circ} \mathrm{C}$ in $4.5 \mathrm{M}$ urea, all 2-AP-substituted hairpin substrates showed distinct fluorescence changes as a function of $\mathrm{Mg}^{2+}$ concentration (Figure 5, solid circles). Addition of $\mathrm{Mg}^{2+}$ resulted in a dramatic increase in fluorescence emission from HP6, as the 2-AP base transitioned from an unfolded and likely partially stacked state into the bulged conformation. 2-AP in the loop region (HP14) exhibited a much more modest enhancement of fluorescence, while emission from the stem-positioned 2-AP residue (HP21) was significantly decreased by $\mathrm{Mg}^{2+}$-dependent stabilization of the folded hairpin structure. Parallel experiments with the 8-mer control oligonucleotides indicated that alterations in local base mobility or interactions with adjacent residues made no significant contributions to $\mathrm{Mg}^{2+}$-induced fluorescence changes. Across the same range of $\mathrm{Mg}^{2+}$ concentrations, fluorescence from the $\mathrm{C} 6, \mathrm{C} 14$ and $\mathrm{C} 21$ substrates exhibited no systematic drift, with variations limited to approximately $4 \%$ (Figure 5, open circles). In addition, modulation of 2-AP photophysics did not contribute to cation-induced changes in fluorescence intensity, since emission from free 2- $\mathrm{AP}$ was insensitive to $\mathrm{Mg}^{2+}$ at concentrations below $25 \mathrm{mM}$ (data not shown). Considering the $\mathrm{Mg}^{2+}$-dependence of hairpin substrate fluorescence as a transition between unfolded and folded hairpin structures permitted quantitative resolution of these data by the Hill model (equation 3). Interestingly, this analysis revealed significantly different $\mathrm{Mg}^{2+}$ requirements for stabilization of RNA folding depending on the position of the 2-AP insertion. Presentation of the bulged base (HP6) was most sensitive to $\mathrm{Mg}^{2+}$, with half-maximal transition observed at $35 \mu \mathrm{M} \mathrm{Mg}^{2+}$ (Table 3). Formation of the stem (HP21) and conformational restraint of the loop insertion (HP14) were observed at significantly higher $\mathrm{Mg}^{2+}$ concentrations. $\mathrm{Mg}^{2+}$-dependent changes in the fluorescence of all 2-AP-substituted hairpin substrates yielded a Hill coefficient near unity, indicating no significant cooperativity with respect to $\mathrm{Mg}^{2+}$. The implications of these data for resolution of RNA folding mechanisms are pursued further under Discussion.

\section{Time-resolved fluorescence properties of 2-AP in diverse RNA structural contexts}

As the model RNA hairpins transition between folded and unfolded states, all three 2-AP substitutions exhibit changes in fluorescence intensity. Time-resolved studies were performed to assess how these processes impact the intrinsic fluorescence properties of 2-AP in each 
structural context. Alterations in fluorescence intensity occur via a variety of photophysical events which can influence fluorescence lifetimes $\left(\tau_{i}\right)$ and/or the relative partitioning between component species $\left(\alpha_{i}\right)$. A representative time-domain experiment comparing the excited state lifetime properties of 2-AP substitutions within the folded HP6 hairpin versus C6 control RNA substrates is shown in Figure 6. Analogous experiments were performed for all hairpin and control substrates under conditions promoting fully folded $\left(5 \mathrm{mM} \mathrm{Mg}(\mathrm{OAc})_{2}, 50 \mathrm{mM} \mathrm{NaOAc}\right)$ or denatured (9 M urea) RNA conformations. In all cases, the lifetime properties of 2-APlabeled RNA substrates were well described $\left(\chi^{2}=0.9-1\right)$ by three component exponential series (Table 4). While at least four discrete 2-AP lifetime components have been described within nucleic acid contexts $(73,74)$, the relatively long pulse width $(500-600 \mathrm{ps})$ of the LED excitation source used in this study precluded accurate resolution of the shortest component, which is often in the $20-60 \mathrm{ps}$ range. Analyses of our data sets using four component exponential series did not significantly improve regression fitness (based on $\chi^{2}$ ), and yielded large uncertainties in the shortest lifetime component. Using the three component algorithm, we expect that contributions from these ultra-fast 2 -AP lifetimes $(<100 \mathrm{ps})$ will be incorporated into the $0.3-1$ ns lifetime component described in this study.

Under fully denatured conditions, the 2-AP residues in hairpin RNA substrates show very similar time-resolved fluorescence properties to those within corresponding control sequences. At $9 \mathrm{M}$ urea, no significant differences were observed between the $\alpha_{i}$ fractions of any hairpin substrate relative to its 8-mer control RNA. Similarly, the 2-AP lifetime components $\left(\tau_{i}\right)$ were largely invariant between hairpin RNAs and cognate control sequences. The sole exception was a small but statistically significant increase (10\%) in the longest 2-AP lifetime component $\left(\tau_{3}\right)$ of the HP6 substrate relative to the C6 RNA. The overall similarity of lifetime parameters from hairpin versus control RNAs suggests that 2-AP largely experiences comparable local environments in these substrates under denaturing conditions. However, the small variation in $\tau_{3}$ between the HP6 and C6 substrates in $9 \mathrm{M}$ urea may account for the difference in 2-AP quantum yield between these RNAs observed by steady-state fluorescence under these conditions (Table 1).

The 8-mer control substrates, which cannot form stable secondary structures, provide a means to monitor stimulus-dependent perturbations of the unfolded state in the absence of secondary RNA structural transitions. 2-AP residues in all control RNAs displayed dramatic changes in $\alpha_{i}$ and $\tau_{i}$ between denaturing versus native solution conditions. In each case, denaturation in 9 M urea substantially decreased $(35-45 \%)$ the fractional contribution of the shortest 2-AP lifetime component $\left(\alpha_{1}\right)$ with concomitant increases in $\alpha_{2}$ and/or $\alpha_{3}$. The 2-AP component lifetimes were also markedly altered by chemical denaturation of each control substrate, with significant increases in both $\tau_{1}$ and $\tau_{2}(27-73 \%$ and $28-68 \%$ versus native conditions, respectively). The longest 2 -AP lifetime component $\left(\tau_{3}\right)$ exhibited small but statistically insignificant decreases following denaturation of each control RNA. One factor contributing to urea-dependent alterations in 2-AP lifetime components may be changes in the intrinsic photophysics of 2-AP itself, possibly due to interaction with the denaturant. To test this possibility, time-domain intensity decay measurements were also taken for free 2-AP in native versus denaturing solution conditions. Addition of urea changed the 2-AP lifetime from a single exponential of $10.9 \pm 0.1 \mathrm{~ns}$ to a biexponential decay with amplitude weighted components of $\alpha_{1}=80 \pm 1 \% ; \tau_{1}=10.64 \pm 0.07 \mathrm{~ns}$ and $\alpha_{2}=20 \pm 3 \% ; \tau_{2}=1.5 \pm 0.3 \mathrm{~ns}$. However, comparing 2-AP lifetime components among different control RNA substrates (Table 4) revealed significant heterogeneity in the magnitude of changes between denaturing versus native conditions. This indicates that interactions between 2 -AP and urea cannot solely account for alterations in the fluorescence of 2-AP-substituted control substrates as they are denatured. Rather, urea-dependent variations in 2-AP stacking with adjacent bases or solvent exposure must also contribute to the altered time-resolved fluorescence properties of this residue in the context of the 8-mer control substrates. 
The preceding experiments show that chemical denaturation can modify the lifetime properties of 2-AP-substituted RNA substrates by influencing both local RNA structure and the photophysics of free 2-AP itself, independent of secondary structural changes in the RNA. As such, interpretation of 2-AP lifetime parameters from hairpin RNA substrates must also consider contributions from these mechanisms. To this end, the influence of secondary RNA structure on the time-resolved fluorescence properties of 2-AP-substituted hairpin substrates was extracted using pair-wise comparisons with data from cognate control RNAs. Under native conditions, 2-AP residues presented in each of the archetypal structural features (bulged base, looped base, and stacked base) show dramatic changes in time-resolved fluorescence properties compared to unstructured control substrates. 2-AP inserted in the bulged position (HP6) displayed significantly longer fluorescence lifetimes for all components (enhancements of 2fold for $\tau_{1}$ and $\tau_{2}$, and $43 \%$ for $\tau_{3}$ ) relative to the cognate control RNA (C6). The trend toward longer 2-AP lifetimes in the bulged position was also reflected in the fractional contributions of the longest lifetime component $\left(\alpha_{3}\right)$, which was enhanced over 5-fold in the HP6 substrate relative to the control sequence at the expense of a nearly $70 \%$ reduction in the amplitude weighting of the shortest lifetime $\left(\alpha_{1}\right)$. Presentation of 2-AP within the loop (HP14) increased fluorescence lifetimes for the intermediate $\left(\tau_{2}\right)$ and longest $\left(\tau_{3}\right)$ components by $13 \%$ and $32 \%$, respectively, while decreasing $\tau_{1}$ by $21 \%$ relative to the control substrate (C14). Concomitantly, the fractional contribution of the intermediate 2-AP lifetime component $\left(\alpha_{2}\right)$ was decreased by $19 \%$ in the loop position versus the C14 RNA. While the contribution of the longest 2-AP lifetime component $\left(\alpha_{3}\right)$ appeared to increase by more than $100 \%$ in the looped conformation relative to control, this result was not statistically significant (at $95 \%$ confidence) across triplicate independent experiments. Unlike HP6 and HP14, where RNA folding enhances 2AP solvent exposure, the folded HP21 substrate positions 2-AP in a base-paired duplex where quenching mechanisms become more prevalent. Although the longest $\left(\tau_{3}\right) 2$-AP lifetime component is modestly increased in HP21 relative to the control substrate (27\% versus $\mathrm{C} 21)$, the fractional contributions of the longer lifetimes $\left(\alpha_{2}, \alpha_{3}\right)$ are both significantly decreased, yielding a $61 \%$ increase in $\alpha_{1}$.

The amplitude-weighted average lifetime $\left(\tau_{a m p}\right)$ is proportional to the area under the steadystate fluorescence emission spectrum in the absence of static quenching mechanisms (75). In this study, the relative differences in $\tau_{a m p}$ values (Table 4 ) between each pair of hairpin and control substrates are similar to the ratio of their steady-state quantum yields (Table 1). For the HP6:C6 and HP14:C14 substrate pairs, longer average lifetimes were reflected in greater steady-state intensities, while in the case of HP21, decreased steady-state fluorescence corresponded to shorter average lifetimes. However, changes in $\tau_{\text {amp }}$ are not necessarily proportional to changes in quantum yield since steady-state fluorescence intensity is sensitive to static quenching caused by aromatic stacking (40) which is not reflected in the average lifetime. Accordingly, resolution of individual component lifetimes and their fractional contributions to total fluorescence are more likely to yield specific metrics that are significantly modulated during conformational changes of 2-AP-substituted RNA substrates.

\section{DISCUSSION}

\section{2-aminopurine as a general sensor of local RNA structure}

In this study, we evaluated the folding of a model RNA substrate from multiple positional perspectives by combining the local environmental sensitivity of 2-AP fluorescence together with new considerations in probe design and comparative controls. Traditional measurements of RNA folding transitions using absorbance spectroscopy detect global conformational events involving significant changes in base-pair potential $(67,76)$. Often, these systems are analyzed using two-state folding models because there is little recourse to do otherwise. However, sitespecific insertion of 2-AP residues can permit much more detailed characterization of RNA 
folding than UV absorbance measurements, since the fluorescence properties of 2-AP in each labeled position are influenced by very local and therefore distinct biochemical environments.

While 2-AP has been used extensively to monitor selected structural elements in nucleic acids including base mismatches, abasic sites, and base flipping, few studies have addressed its ability to detect hybridization or more subtle local conformational events. Here, presentation of 2-AP in a base-paired region (HP21) significantly decreased fluorescence quantum yield relative to 2-AP residues in regions of greater solvent exposure, allowing transitions between locally paired and unpaired conformations to be resolved by changes in steady-state fluorescence. More notably, formation of an RNA loop could be monitored by enhanced emission from a 2-AP residue inserted within the loop itself (HP14). While the dynamic range of this transition was limited, defined thermodynamic behavior was resolvable following correction for primary structural and/or non-specific 2-AP photophysical effects (eg: Figure 3 and Figure 4). Furthermore, placement of 2-AP in bulged, looped, or base-paired RNA conformations yielded unique changes in time-resolved fluorescence properties relative to unstructured RNA controls, involving modulation of specific lifetime components $\left(\tau_{i}\right)$ and/or their fractional contributions to 2-AP fluorescence $\left(\alpha_{i}\right)$. Conceivably, changes in 2-AP fluorescence accompanying RNA conformational transitions may reflect changes in local base stacking, solvent exposure, base pairing, or proximity to localized cations resulting from RNA folding. Together, these data demonstrate that insertion of 2-AP into any of these distinct RNA structural environments imparts specific characteristics to fluorescence emission from this residue, which may be detected by steady-state or time-resolved fluorescence spectroscopic techniques.

\section{Detection of site-specific variations in RNA folding and unfolding processes}

Urea titration experiments indicated that the local RNA structural environment was most stable for 2-AP substituted in the loop position, but that the conformation of this region was also most sensitive to the presence of the denaturant (Table 2). However, the enhanced stability of the loop region was not reflected in thermal denaturation experiments conducted in the absence of urea (Table 2), indicating that local conformational events in the native hairpin are differentially modulated by the denaturation method employed.

$\mathrm{Mg}^{2+}$ titrations were used to re-fold urea-denatured hairpin RNA substrates, permitting local features of RNA hairpin folding to be evaluated by $\mathrm{Mg}^{2+}$-dependent changes in 2-AP fluorescence (Table 3). Preferential enhancement of 2-AP fluorescence in the bulged position (HP6) at low concentrations of $\mathrm{Mg}^{2+}$ suggests that RNA conformational changes promoting solvent exposure of the adenine (or 2-AP) in position 6 are stabilized at much lower $\mathrm{Mg}^{2+}$ concentrations than those necessary to drive 2-AP stacking in the stem position (HP21). Higher $\mathrm{Mg}^{2+}$ concentrations are also required to stabilize the local environment of the loop region, possibly by limiting the segmental dynamics of looped bases. These position-dependent differences in the sensitivity of fluorescence emission from 2-AP-labeled hairpin substrates to $\mathrm{Mg}^{2+}$-stabilized RNA folding were in marked contrast to the $\mathrm{Mg}^{2+}$ sensitivity of global hairpin RNA folding. While half-maximal folding of all hairpin substrates was observed at similar $\mathrm{Mg}^{2+}$ concentrations by UV absorbance (Figure $\mathrm{S} 1$ ), this revealed no information about localized structural events contributing to the conformational transition. Together, these experiments show that the exquisite sensitivity of 2-AP fluorescence to local environmental conditions allows regio-specific characterization of structural transitions within this model RNA hairpin, to a degree not easily accessible by methods measuring only global structural changes. An independent group used a similar rationale to kinetically monitor local conformational events within the hammerhead ribozyme. There, temperature-jump experiments permitted the rapid local dynamics of a 2-AP residue inserted within the tetraloop to be distinguished from slower dynamics within the core near the cleavage site (21). 
Fluorescence lifetimes can be highly sensitive to changes in the local environment of the fluorophore, exemplified by increases in the longest 2-AP lifetimes $\left(\tau_{3}\right)$ of all hairpin substrates relative to unstructured control sequences (Table 4). However, in many cases, the changes in component lifetimes may be small relative to alterations in their fractional contributions to 2AP fluorescence. For example, the fractional contribution of the shortest 2-AP lifetime $\left(\alpha_{1}\right)$ is dramatically enhanced when base-paired (HP21), but is diminished in a bulged base (HP6). The sensitivity of $\alpha_{i}$ to conformational dynamics has also been exhibited in protein-DNA interactions (77). Conversely, this parameter is not significantly modified by localization of 2AP in the loop position (HP14); rather, contributions from the intermediate 2-AP lifetime $\left(\alpha_{2}\right)$ are diminished in this conformation. Current understanding is that 2-AP component lifetimes are strongly influenced by local base stacking in the context of nucleic acids, where enhanced stacking potential is associated with higher fractional contributions from shorter lifetime components $(36,73,74)$. As such, evaluation of local RNA folding thermodynamics may be dramatically enhanced by monitoring individual 2-AP lifetime components and/or fractional contributions as the RNA conformation transitions from one state to another.

\section{Utilization of reference states and control sequences}

Several observations arising from this study underscored the importance of appropriate controls when using fluorescent base analogue probes to evaluate conformational changes in nucleic acids. Here, we used unstructured control RNA substrates to discriminate the contributions of higher-order RNA structures on 2-AP fluorescence from stimulus-dependent changes in intrinsic 2-AP photophysics and/or interactions with adjacent residues. For steady-state fluorescence measurements, 2-AP intensity changes resulting from secondary structural transitions were resolved by ratiometric normalization of hairpin substrate fluorescence to control RNA emission under identical solution conditions. The utility of this approach was exemplified by the urea denaturation experiments (Figure 4), where thermodynamic parameters describing conformational transitions could be extracted from urea-dependent changes in hairpin fluorescence which otherwise demonstrated more complex behavior. On the other hand, thermal denaturation analyses showed comparable $T_{m}$ values with and without ratiometric correction ( $c f$. Table 2 and Table S1). Because the temperature dependence of control RNA fluorescence is relatively monotonic for the control substrates studied here (Figure S2), its principal influence on these data was to alter the magnitude of the derivative functions, not the position(s) of local extremes. However, emission from control RNA substrates was often differentially sensitive to thermal or chemical perturbation (e.g., Figures S2 and S5), indicating that parallel measurements of fluorescence from 2-AP-substituted hairpin and corresponding control substrates are required for every set of solution conditions. For time-resolved fluorescence measurements, direct comparison of component 2-AP lifetimes $\left(\tau_{i}\right)$ and their associated fractional contributions $\left(\alpha_{i}\right)$ between hairpin and cognate control RNA substrates revealed unique fluorescence lifetime parameters associated with 2-AP insertions in each RNA structural context. Assignment of secondary structural influences to each parameter based on differences between 2-AP fluorescence in the folded hairpin versus 8-mer control contexts was further validated by the convergence of lifetime parameters in each hairpin:control substrate set under fully denatured conditions.

\section{Considerations in probe design}

For analyses of RNA conformational events, optimally designed 2-AP-substituted RNA sequences will exhibit several features: [i] maximal dynamic range across the folding transition, [ii] high sensitivity to the process of interest, [iii] low sensitivity to concurrent but unrelated processes, and [iv] reasonable chemical/spectroscopic stability. 2-AP exhibited negligible photobleaching under the conditions employed in this study (data not shown) and has shown robust photostability under much stronger excitation (78). The red-shifted absorption spectrum also allows selective 2-AP excitation in the presence of other nucleic acids 
and proteins (1). However, as noted above, 2-AP fluorescence is very sensitive to both its local environment and to the presence and identity of neighboring nucleotides (Ref. 32,Ref. 33, Ref. 35 and this work). For example, guanosine efficiently quenches 2-AP fluorescence via electron transfer $(34,39,79)$, accounting for the potent loss of emission observed in systems where 2AP can collide with neighboring guanosine residues (38). Conversely, a stack of adenine residues can act as an antenna, directing excitation energy into 2-AP (35). This effect may account for the enhanced quantum yield of 2-AP observed in the C14 substrate relative to the other 8-mer control RNAs (Table 1).

Direct interaction with adjacent bases quenches 2-AP fluorescence by both static and dynamic mechanisms (40). Accordingly, 2-AP labeling positions that experience significant changes in base stacking potential will yield the greatest dynamic ranges of fluorescence emission in response to RNA conformational changes (eg: HP6). However, such placement may be undesirable in some situations due to potential interference with protein binding or tertiary RNA structural events. Based on the data presented in this work, even very modest alterations in local base stacking (eg: HP14) can be resolved by 2-AP fluorescence if rigorous controls are employed. A more frequent scenario occurs when the specific secondary and/or tertiary structural environment of a given base is unknown. For such cases, comparison of timeresolved fluorescence properties relative to minimally structured control substrates can reveal information about the local RNA conformation near specific residues based on characteristic lifetime parameters inherent to 2-AP in different structural contexts (Table 4). Taken together, these studies illustrate the broad applicability of 2-AP fluorescence in the structural and thermodynamic characterization of diverse RNA conformational events.

\section{ACKNOWLEDGEMENT}

We thank James Prevas for valuable technical assistance.

\section{REFERENCES}

1. Ward DC, Reich E, Stryer L. Fluorescence studies of nucleotides and polynucleotides. I. Formycin, 2-aminopurine riboside, 2,6-diaminopurine riboside, and their derivatives. J. Biol. Chem 1969;244:1228-1237. [PubMed: 5767305]

2. Rist MJ, Marino JP. Fluorescent nucleotide base analogs as probes of nucleic acid structure, dynamics and interactions. Curr. Org. Chem 2002;6:775-793.

3. Millar DP. Fluorescence studies of DNA and RNA structure and dynamics. Curr. Opin. Struct. Biol 1996;6:322-326. [PubMed: 8804835]

4. O'Neill MA, Barton JK. 2-aminopurine: A probe of structural dynamics and charge transfer in DNA and DNA:RNA hybrids. J. Am. Chem. Soc 2002;124:13053-13066. [PubMed: 12405832]

5. Jean JM, Hall KB. Stacking-unstacking dynamics of oligodeoxynucleotide trimers. Biochemistry 2004;43:10277-10284. [PubMed: 15287755]

6. Menger M, Eckstein F, Porschke D. Dynamics of the RNA hairpin GNRA tetraloop. Biochemistry 2000;39:4500-4507. [PubMed: 10757999]

7. Rist M, Marino J. Association of an RNA kissing complex analyzed using 2-aminopurine fluorescence. Nucleic Acids Res 2001;29:2401-2408. [PubMed: 11376159]

8. Bernards AS, Miller JK, Bao KK, Wong I. Flipping duplex DNA inside out - A double base-flipping reaction mechanism by Escherichia coli MutY adenine glycosylase. J. Biol. Chem 2002;277:2096020964. [PubMed: 11964390]

9. Law SM, Eritja R, Goodman MF, Breslauer KJ. Spectroscopic and calorimetric characterizations of DNA duplexes containing 2-aminopurine. Biochemistry 1996;35:12329-12337. [PubMed: 8823167]

10. Rachofsky EL, Seibert E, Stivers JT, Osman R, Ross JBA. Conformation and dynamics of abasic sites in DNA investigated by time-resolved fluorescence of 2-aminopurine. Biochemistry 2001;40:957-967. [PubMed: 11170417] 
11. Stivers JT. 2-Aminopurine fluorescence studies of base stacking interactions at abasic sites in DNA: metal-ion and base sequence effects. Nucleic Acids Res 1998;26:3837-3844. [PubMed: 9685503]

12. Pompizi I, Haberli A, Leumann CJ. Oligodeoxynucleotides containing conformationally constrained abasic sites: a UV and fluorescence spectroscopic investigation on duplex stability and structure. Nucleic Acids Res 2000;28:2702-2708. [PubMed: 10908326]

13. Holz B, Klimasauskas S, Serva S, Weinhold E. 2-Aminopurine as a fluorescent probe for DNA base flipping by methyltransferases. Nucleic Acids Res 1998;26:1076-1083. [PubMed: 9461471]

14. Neely RK, Daujotyte D, Grazulis S, Magennis SW, Dryden DTF, Klimasauskas S, Jones AC. Timeresolved fluorescence of 2-aminopurine as a probe of base flipping in M.HhaI-DNA complexes. Nucleic Acids Res 2005;33:6953-6960. [PubMed: 16340006]

15. Hariharan C, Reha-Krantz LJ. Using 2-aminopurine fluorescence to detect bacteriophage T4 DNA polymerase-DNA complexes that are important for primer extension and proofreading reactions. Biochemistry 2005;44:15674-15684. [PubMed: 16313170]

16. Myers JC, Shamoo Y. Human UP1 as a model for understanding purine recognition in the family of proteins containing the RNA recognition motif (RRM). J. Mol. Biol 2004;342:743-756. [PubMed: 15342234]

17. Austin RJ, Xia TB, Ren JS, Takahashi TT, Roberts RW. Differential modes of recognition in N peptide-boxB complexes. Biochemistry 2003;42:14957-14967. [PubMed: 14674772]

18. Xia T, Becker HC, Wan C, Frankel A, Roberts RW, Zewail AH. The RNA-protein complex: Direct probing of the interfacial recognition dynamics and its correlation with biological functions. Proc. Natl. Acad. Sci. USA 2003;100:8119-8123. [PubMed: 12815093]

19. Walter NG, Harris DA, Pereira MJB, Rueda D. In the fluorescent spotlight: Global and local conformational changes of small catalytic RNAs. Biopolymers 2001;61:224-242. [PubMed: 11987183]

20. Menger M, Tuschl T, Eckstein F, Porschke D. $\mathrm{Mg}^{2+}$-dependent conformational changes in the hammerhead ribozyme. Biochemistry 1996;35:14710-14716. [PubMed: 8942631]

21. Menger M, Eckstein F, Porschke D. Multiple conformational states of the hammerhead ribozyme, broad time range of relaxation and topology of dynamics. Nucleic Acids Res 2000;28:4428-4434. [PubMed: 11071929]

22. Harris DA, Rueda D, Walter NG. Local conformational changes in the catalytic core of the transacting hepatitis delta virus ribozyme accompany catalysis. Biochemistry 2002;41:12051-12061. [PubMed: 12356305]

23. Walter NG, Chan PA, Hampel KJ, Millar DP, Burke JM. A base change in the catalytic core of the hairpin ribozyme perturbs function but not domain docking. Biochemistry 2001;40:2580-2587. [PubMed: 11327881]

24. Wickiser JK, Cheah MT, Breaker RR, Crothers DM. The kinetics of ligand binding by an adeninesensing riboswitch. Biochemistry 2005;44:13404-13414. [PubMed: 16201765]

25. Purohit V, Grindley NDF, Joyce CM. Use of 2-aminopurine fluorescence to examine conformational changes during nucleotide incorporation by DNA polymerase I (Klenow fragment). Biochemistry 2003;42:10200-10211. [PubMed: 12939148]

26. Dunlap CA, Tsai MD. Use of 2-aminopurine and tryptophan fluorescence as probes in kinetic analyses of DNA polymerase $\beta$. Biochemistry 2002;41:11226-11235. [PubMed: 12220188]

27. da Silva EF, Mandal SS, Reha-Krantz LJ. Using 2-aminopurine fluorescence to measure incorporation of incorrect nucleotides by wild type and mutant bacteriophage T4 DNA polymerases. J. Biol. Chem 2002;277:40640-40649. [PubMed: 12189135]

28. Kaul M, Barbieri CM, Pilch DS. Defining the basis for the specificity of aminoglycoside-rRNA recognition: A comparative study of drug binding to the A sites of Escherichia coli and human rRNA. J. Mol. Biol 2005;346:119-134. [PubMed: 15663932]

29. Kaul M, Barbieri CM, Pilch DS. Fluorescence-based approach for detecting and characterizing anti biotic-induced conformational changes in ribosomal RNA: Comparing aminoglycoside binding to prokaryotic and eukaryotic ribosomal RNA sequences. J. Am. Chem. Soc 2004;126:3447-3453. [PubMed: 15025471]

30. Bradick TD, Marino JP. Ligand-induced changes in 2-aminopurine fluorescence as a probe for small molecule binding to HIV-1 TAR RNA. RNA 2004;10:1459-1468. [PubMed: 15273324] 
31. Patel N, Berglund H, Nilsson L, Rigler R, McLaughlin LW, Graslund A. Thermodynamics of interaction of a fluorescent DNA oligomer with the antitumor drug netropsin. Eur. J. Biochem 1992;203:361-366. [PubMed: 1310467]

32. Davis SP, Matsumura M, Williams A, Nordlund TM. Position dependence of 2-aminopurine spectra in adenosine pentadeoxynucleotides. J. Fluoresc 2003;13:249-259.

33. Rai P, Cole TD, Thompson E, Millar DP, Linn S. Steady-state and time-resolved fluorescence studies indicate an unusual conformation of 2-aminopurine within ATAT and TATA duplex DNA sequences. Nucleic Acids Res 2003;31:2323-2332. [PubMed: 12711677]

34. Somsen OJG, Hoek VA, Amerongen VH. Fluorescence quenching of 2-aminopurine in dinucleotides. Chem. Phys. Lett 2005;402:61-65.

35. Xu DG, Nordlund TM. Sequence dependence of energy transfer in DNA oligonucleotides. Biophys. J 2000;78:1042-1058. [PubMed: 10653818]

36. Hall KB, Williams JD. Dynamics of the IRE RNA hairpin loop probed by 2-aminopurine fluorescence and stochastic dynamics simulations. RNA 2004;10:34-47. [PubMed: 14681583]

37. Jean JM, Krueger BP. Structural fluctuations and excitation transfer between adenine and 2aminopurine in single-stranded deoxytrinucleotides. J. Phys. Chem. B 2006;110:2899-2909. [PubMed: 16471900]

38. O'Neill MA, Barton JK. DNA-mediated charge transport requires conformational motion of the DNA bases: Elimination of charge transport in rigid glasses at 77 K. J. Am. Chem. Soc 2004;126:1323413235. [PubMed: 15479072]

39. Kelley SO, Barton JK. Electron transfer between bases in double helical DNA. Science 1999;283:375381. [PubMed: 9888851]

40. Rachofsky EL, Osman R, Ross JBA. Probing structure and dynamics of DNA with 2-aminopurine: Effects of local environment on fluorescence. Biochemistry 2001;40:946-956. [PubMed: 11170416]

41. Hardman SJO, Thompson KC. Influence of base stacking and hydrogen bonding on the fluorescence of 2-aminopurine and pyrrolocytosine in nucleic acids. Biochemistry 2006;45:9145-9155. [PubMed: 16866360]

42. Jean JM, Hall KB. 2-Aminopurine fluorescence quenching and lifetimes: Role of base stacking. Proc. Natl. Acad. Sci. USA 2001;98:37-41. [PubMed: 11120885]

43. Jean JM, Hall KB. 2-Aminopurine electronic structure and fluorescence properties in DNA. Biochemistry 2002;41:13152-13161. [PubMed: 12403616]

44. O'Neill MA, Dohno C, Barton JK. Direct chemical evidence for charge transfer between photoexcited 2-aminopurine and guanine in duplex DNA. J. Am. Chem. Soc 2004;126:1316-1317. [PubMed: 14759170]

45. Fiebig T, Wan CZ, Zewail AH. Femtosecond charge transfer dynamics of a modified DNA base: 2aminopurine in complexes with nucleotides. ChemPhysChem 2002;3:781-788. [PubMed: 12436905]

46. Larsen OFA, van Stokkum IHM, de Weerd FL, Vengris M, Aravindakumar CT, van Grondelle R, Geacintov NE, van Amerongen H. Ultrafast transient-absorption and steady-state fluorescence measurements on 2-aminopurine substituted dinucleotides and 2-aminopurine substituted DNA duplexes. Phys. Chem. Chem. Phys 2004;6:154-160.

47. Clerte C, Hall KB. Global and local dynamics of the U1A polyadenylation inhibition element (PIE) RNA and PIE RNA-U1A complexes. Biochemistry 2004;43:13404-13415. [PubMed: 15491147]

48. Jaeger JA, SantaLucia J Jr, Tinoco I Jr. Determination of RNA structure and thermodynamics. Ann. Rev. Biochem 1993;62:255-287. [PubMed: 7688943]

49. Doudna JA. A molecular contortionist. Nature 1997;388:830. [PubMed: 9278040]

50. Wilson GM, Sun Y, Lu H, Brewer G. Assembly of AUF1 oligomers on U-rich RNA targets by sequential dimer association. J. Biol. Chem 1999;274:33374-33381. [PubMed: 10559216]

51. Ford LP, Wilusz J. An in vitro system using HeLa cytoplasmic extracts that reproduces regulated mRNA stability. Methods 1999;17:21-27. [PubMed: 10075879]

52. Fialcowitz EJ, Brewer BY, Keenan BP, Wilson GM. A hairpin-like structure within an AU-rich mRNA-destabilizing element regulates trans-factor binding selectivity and mRNA decay kinetics. J. Biol. Chem 2005;280:22406-22417. [PubMed: 15809297] 
53. Santoro MM, Bolen DW. Unfolding free energy changes determined by the linear extrapolation method. 1. Unfolding of phenylmethanesulfonyl $\alpha$-chymotrypsin using different denaturants. Biochemistry 1988;27:8063-8068. [PubMed: 3233195]

54. Manyusa S, Whitford D. Defining folding and unfolding reactions of apocytochrome $b_{5}$ using equilibrium and kinetic fluorescence measurements. Biochemistry 1999;38:9533-9540. [PubMed: 10413531]

55. Heilman-Miller SL, Thirumalai D, Woodson SA. Role of counterion condensation in folding of the Tetrahymena ribozyme. I. Equilibrium stabilization by cations. J. Mol. Biol 2001;306:1157-1166. [PubMed: 11237624]

56. Hermann T, Patel DJ. RNA bulges as architectural and recognition motifs. Structure 2000;8:R47R54. [PubMed: 10745015]

57. Borer PN, Lin Y, Wang S, Roggenbuck MW, Gott JM, Uhlenbeck OC, Pelczer I. Proton NMR and structural features of a 24-nucleotide RNA hairpin. Biochemistry 1995;34:6488-6503. [PubMed: 7756280]

58. Greenbaum NL, Radhakrishnan I, Patel DJ, Hirsh D. Solution structure of the donor site of a transsplicing RNA. Structure 1996;4:725-733. [PubMed: 8805553]

59. Berglund JA, Rosbash M, Schultz SC. Crystal structure of a model branchpoint-U2 snRNA duplex containing bulged adenosines. RNA 2001;7:682-691. [PubMed: 11350032]

60. Ennifar E, Dumas P. Polymorphism of bulged-out residues in HIV-1 RNA DIS kissing complex and structure comparison with solution studies. J. Mol. Biol 2006;356:771-782. [PubMed: 16403527]

61. Colvin RA, White SW, Garcia-Blanco MA, Hoffman DW. Structural features of an RNA containing the CUGGGA loop of the human immunodeficiency virus type 1 trans-activation response element. Biochemistry 1993;32:1105-1112. [PubMed: 8424939]

62. Jaeger JA, Tinoco I. An NMR study of the HIV-1 TAR element hairpin. Biochemistry 1993;32:12522-12530. [PubMed: 8241143]

63. Klinck R, Sprules T, Gehring K. Structural characterization of three RNA hexanucleotide loops from the internal ribosome entry site of polioviruses. Nucleic Acids Res 1997;25:2129-2137. [PubMed: 9153312]

64. Zuker M. Mfold web server for nucleic acid folding and hybridization prediction. Nucleic Acids Res 2003;31:3406-3415. [PubMed: 12824337]

65. Mathews DH, Sabina J, Zuker M, Turner DH. Expanded sequence dependence of thermodynamic parameters improves prediction of RNA secondary structure. J. Mol. Biol 1999;288:911-940. [PubMed: 10329189]

66. Jiao YG, Stringfellow S, Yu HT. Distinguishing "looped-out" and "stacked-in" DNA bulge conformation using fluorescent 2-aminopurine replacing a purine base. J. Biomol. Struct. Dyn 2002;19:929-934. [PubMed: 11922846]

67. Draper DE, Gluick TC. Melting studies of RNA unfolding and RNA-ligand interactions. Methods Enzymol 1995;259:281-305. [PubMed: 8538459]

68. Shelton VM, Sosnick TR, Pan T. Applicability of urea in the thermodynamic analysis of secondary and tertiary RNA folding. Biochemistry 1999;38:16831-16839. [PubMed: 10606516]

69. Pan J, Thirumalai D, Woodson SA. Magnesium-dependent folding of self-splicing RNA: Exploring the link between cooperativity, thermodynamics, and kinetics. Proc. Natl. Acad. Sci. USA 1999;96:6149-6154. [PubMed: 10339556]

70. Draper DE. A guide to ions and RNA structure. RNA 2004;10:335-343. [PubMed: 14970378]

71. Wilson GM, Sutphen K, Moutafis M, Sinha S, Brewer G. Structural remodeling of an A+U-rich RNA element by cation or AUF1 binding. J. Biol. Chem 2001;276:38400-38409. [PubMed: 11514570]

72. Wilson TJ, Lilley DMJ. Metal ion binding and the folding of the hairpin ribozyme. RNA 2002;8:587600. [PubMed: 12022226]

73. Guest CR, Hochstrasser RA, Sowers LC, Millar DP. Dynamics of mismatched base pairs in DNA. Biochemistry 1991;30:3271-3279. [PubMed: 2009265]

74. Gondert ME, Tinsley RA, Rueda D, Walter NG. Catalytic core structure of the trans-acting HDV ribozyme is subtly influenced by sequence variation outside the core. Biochemistry 2006;45:75637573. [PubMed: 16768452] 
75. Lakowicz, JR. Principles of Fluorescence Spectroscopy. New York, NY: Kluwer Academic/Plenum; 1999.

76. Breslauer KJ. Extracting thermodynamic data from equilibrium melting curves for oligonucleotide order-disorder transitions. Methods Enzymol 1995;259:221-242. [PubMed: 8538456]

77. Hochstrasser RA, Carver TE, Sowers LC, Millar DP. Melting of a DNA helix terminus within the active site of a DNA polymerase. Biochemistry 1994;33:11971-11979. [PubMed: 7918416]

78. Ye JY, Ishikawa M, Yamane Y, Tsurumachi N, Nakatsuka H. Enhancement of two-photon excited fluorescence using one-dimensional photonic crystals. Appl. Phys. Lett 1999;75:3605-3607.

79. Holmen A, Norden B, Albinsson B. Electronic transition moments of 2-aminopurine. J. Am. Chem. Soc 1997;119:3114-3121.

\section{Abbreviations}

2-AP, 2-aminopurine. 


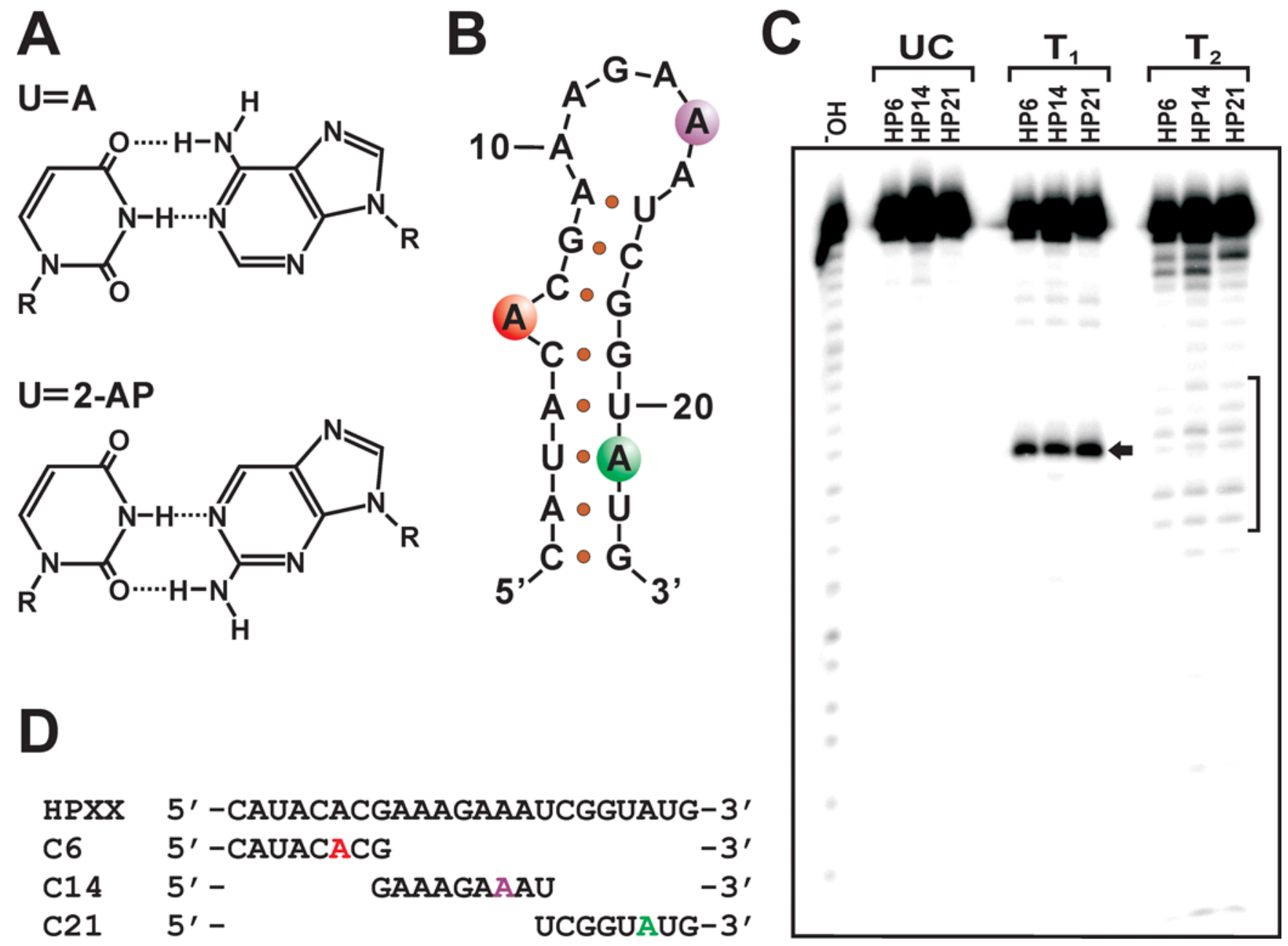

FIGURE 1.

Structure of 2-AP-labeled RNA substrates. (A) Structural formulae of U:A and U:2-AP base pairs. (B) mFold-predicted structure of hairpin RNA substrates. Spheres denote the sites of specific 2-AP substitutions (6 position in red, 14 position in purple, 21 position in green). (C) Nuclease footprinting of folded hairpin substrates, comparing uncut (UC), RNase $\mathrm{T}_{1}$-digested $\left(\mathrm{T}_{1}\right)$, and RNase $\mathrm{T}_{2}$-digested $\left(\mathrm{T}_{2}\right)$ RNAs. The lane designated "- $\mathrm{OH}$ " is a sequence ladder generated via limited alkaline hydrolysis of HP14. The black arrow denotes RNase $\mathrm{T}_{1}$-directed cleavage at nucleotide G12, and the bracket indicates preferential RNase $\mathrm{T}_{2}$ cleavage sites at positions 10-15. (D) Sequence alignment of each of the 8-mer control RNAs with the hairpin substrate. 2-AP was inserted as the sixth nucleotide for each control RNA, analogous to the position of the 2-AP substitution in each corresponding full length hairpin. 

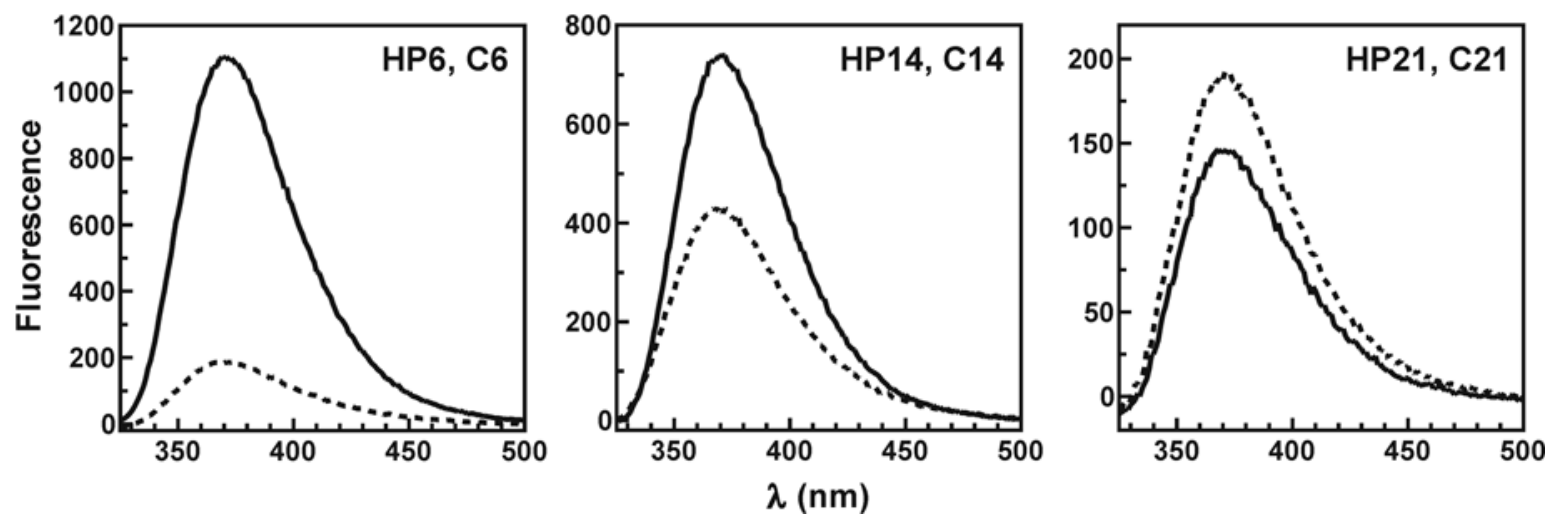

FIGURE 2.

Emission spectra of 2-AP-substituted RNA oligonucleotides. Fluorescence $\left(\lambda_{\mathrm{ex}}=303 \mathrm{~nm}\right)$ of RNA hairpins (solid lines) and control sequences (dashed lines) was measured under native conditions (10 mM KHEPES ( $\mathrm{pH} 7.4), 50 \mathrm{mM} \mathrm{KOAc,} 5 \mathrm{mM} \mathrm{Mg}(\mathrm{OAc})_{2}$ ) at $25^{\circ} \mathrm{C}$ using 300 $\mathrm{nM}$ of each RNA substrate. 

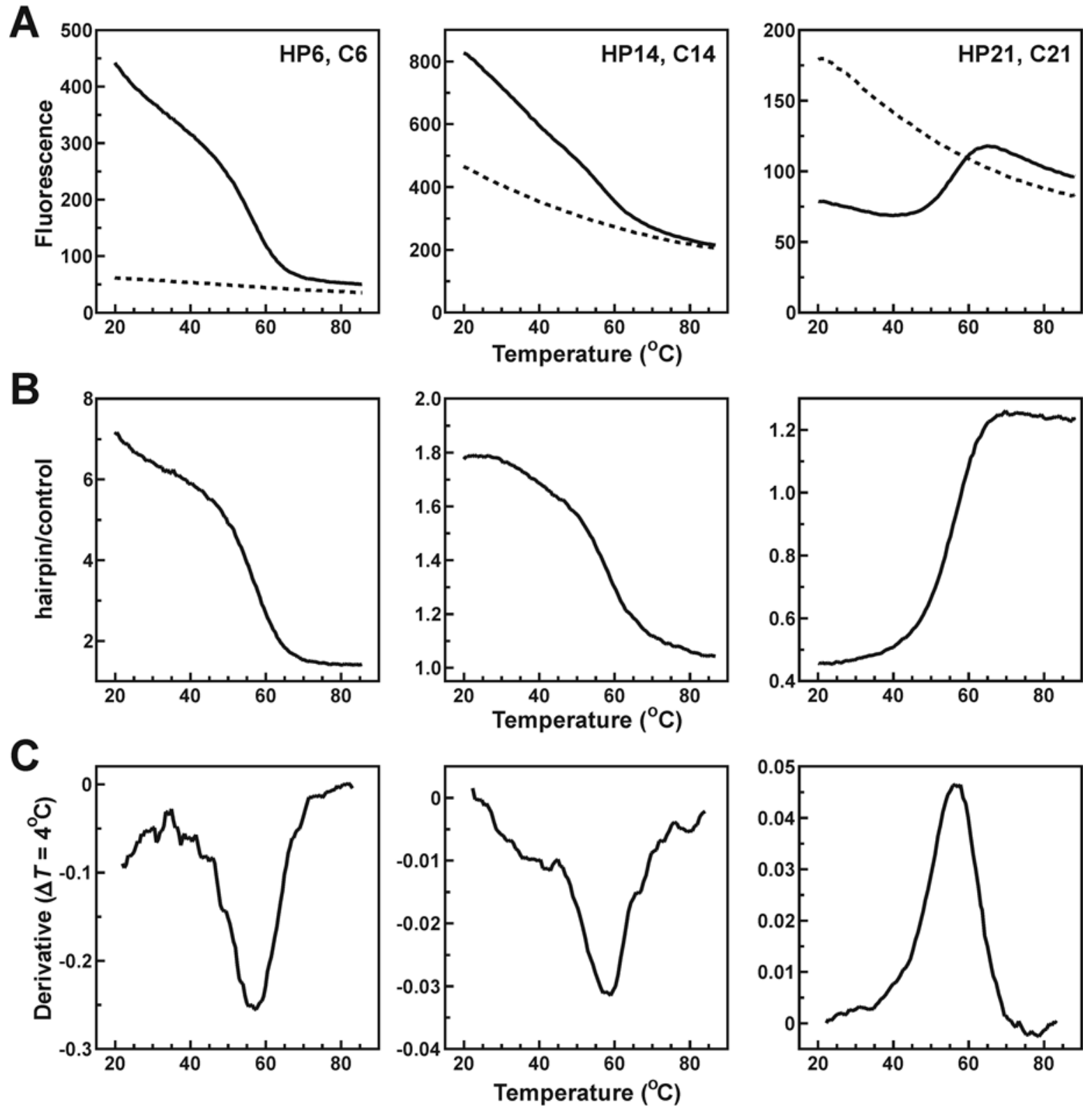

FIGURE 3.

Thermal denaturation analyses of 2-AP-substituted RNA substrates. (A) Blank-corrected fluorescence $\left(\lambda_{\mathrm{ex}}=303 \mathrm{~nm} ; \lambda_{\mathrm{em}}=370 \mathrm{~nm}\right)$ of hairpin (solid lines) and control (dashed lines) RNA substrates was measured under native conditions (10 mM KHEPES (pH 7.4), $50 \mathrm{mM}$ $\left.\mathrm{KOAc}, 5 \mathrm{mM} \mathrm{Mg}(\mathrm{OAc})_{2}\right)$ as a function of temperature. To improve signal-to-noise, HP14, C14, HP21, and C21 samples were measured at $750 \mathrm{nM}$ with $10 \mathrm{~nm}$ emission slits. (B) Fluorescence intensity values from hairpin substrates were normalized to emission from cognate 8-mer control RNA sequences at each measured temperature. (C) These controlcorrected hairpin emission values were then used to construct derivative plots as a function of temperature $\left(\Delta T=4{ }^{\circ} \mathrm{C}\right)$, permitting estimation of transition melting temperatures $\left(T_{m}\right)$ listed in Table 2. 

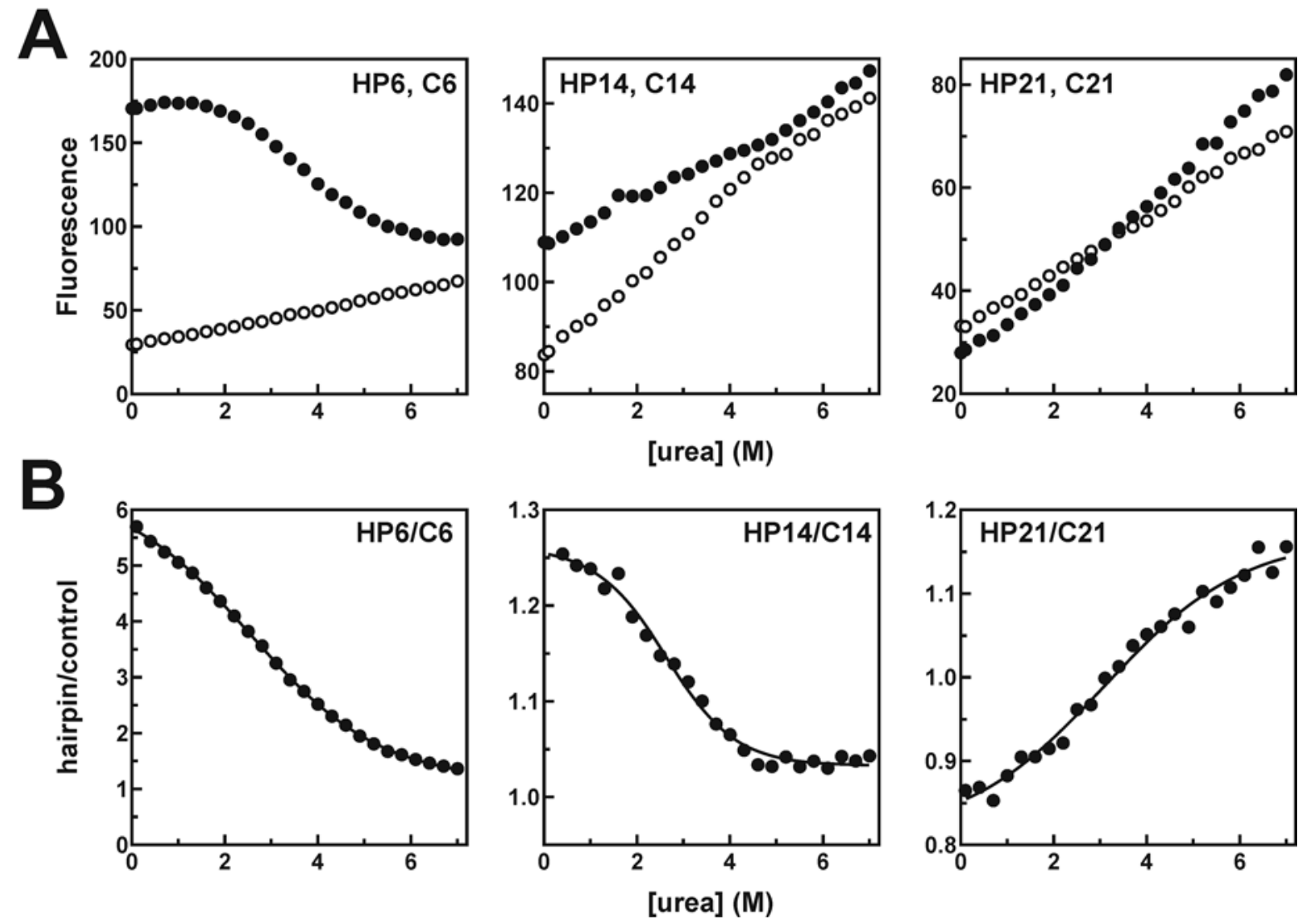

FIGURE 4.

Chemical denaturation of 2-AP-substituted RNA substrates. (A) Blank-corrected fluorescence from hairpin (solid circles) and control (open circles) RNA substrates was measured at $10 \mathrm{mM}$ KHEPES (pH 7.4) across a titration of urea at $25^{\circ} \mathrm{C}$. (B) Fluorescence intensity values from hairpin substrates were normalized to emission from cognate 8-mer control RNA sequences at each urea concentration. Parameters relating the thermodynamics of urea-dependent RNA unfolding were estimated using a two-state model as described under Experimental Procedures (solid lines) and are listed in Table 2. 

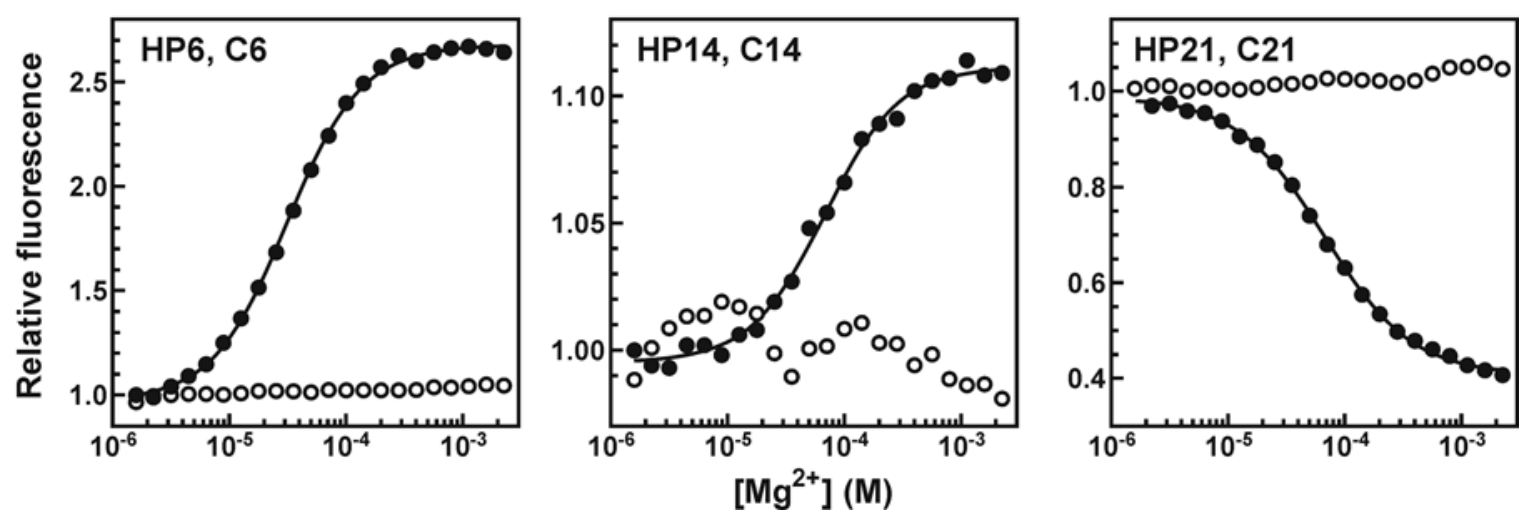

FIGURE 5.

Magnesium-stabilized folding of hairpin RNA substrates in 4.5 M urea. The fluorescence intensities of hairpin (solid circles) and 8-mer control (open circles) RNA substrates were measured as a function of $\mathrm{Mg}^{2+}$ concentration at $25^{\circ} \mathrm{C}$, and plotted relative to the emission from each substrate in the absence of added $\mathrm{Mg}^{2+}$. Data were resolved by nonlinear regression using the cooperative Hill equation (eq. 3, solid lines). Averaged regression parameters from five independent experiments are listed in Table 3. 


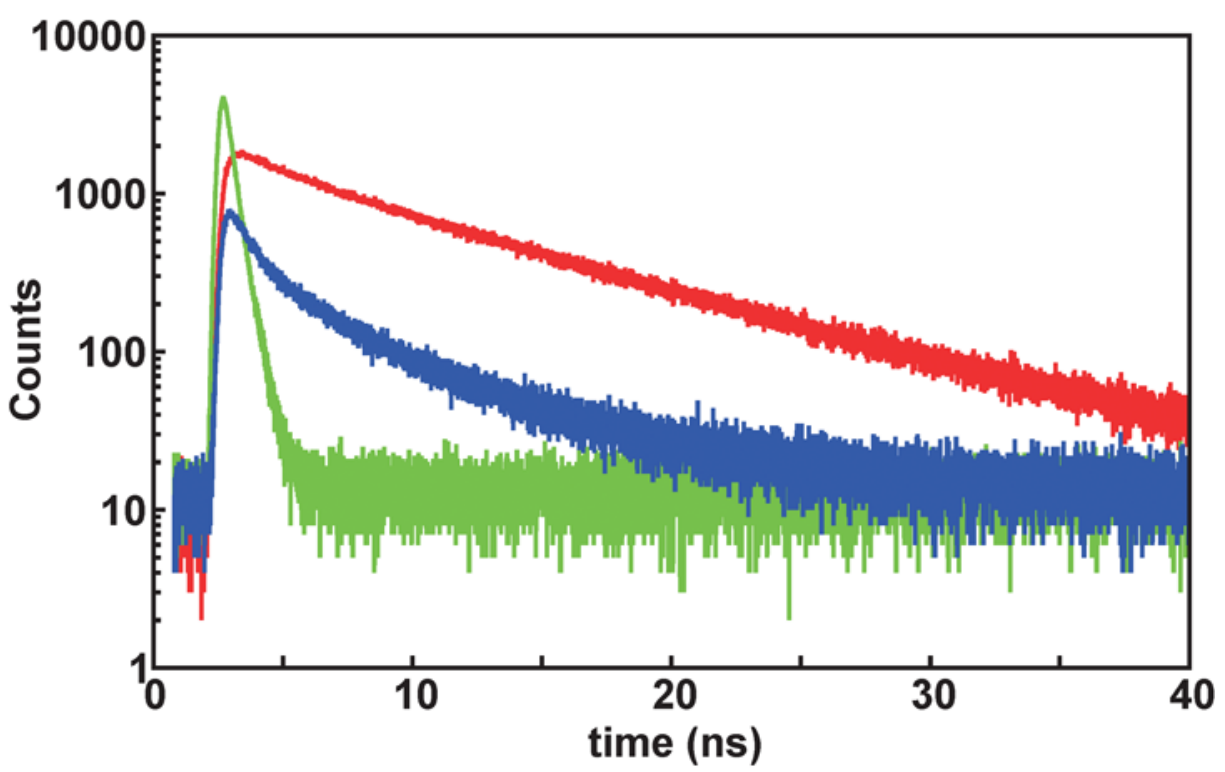

HP6 substrate

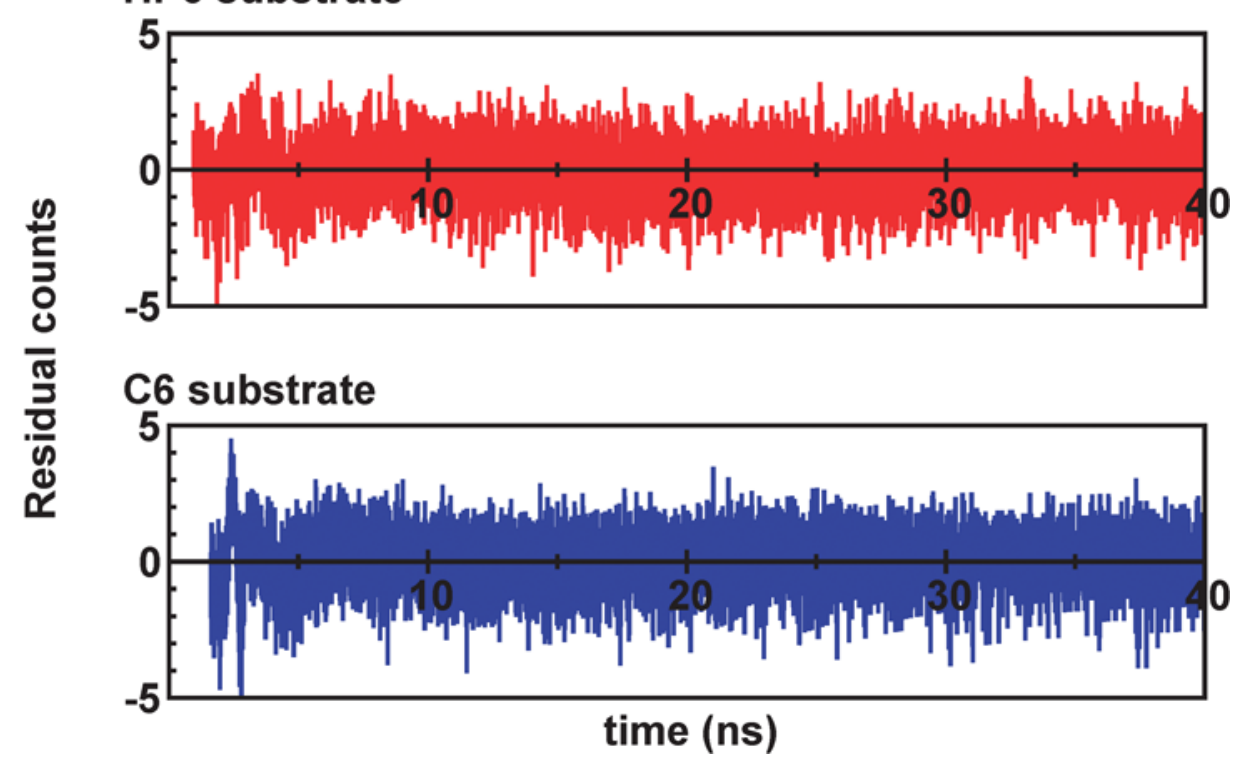

FIGURE 6.

Time-domain intensity decay of HP6 (red) and C6 (blue) RNA substrates following excitation at $295 \mathrm{~nm}$ ( $3 \mu \mathrm{M}$ RNA in $10 \mathrm{mM}$ NaHEPES ( $\left.\mathrm{pH} 7.4), 50 \mathrm{mM} \mathrm{NaOAc}, 5 \mathrm{mM} \mathrm{Mg}(\mathrm{OAc})_{2}\right)$ at $22{ }^{\circ} \mathrm{C}$. The instrument response function is shown in green. Residual plots from nonlinear regression of 2-AP fluorescence decay data to three component exponential series based on eq. 4 are shown below. Lifetime parameters calculated from regression series are summarized in Table 4. 
Table 1

Relative quantum yields of RNA substrates ${ }^{a}$

\begin{tabular}{ccc}
\hline RNA substrate & Native conditions $^{\boldsymbol{b}}$ & Denaturing conditions $^{\boldsymbol{c}}$ \\
\hline HP6 & $0.341 \pm 0.026$ & $0.186 \pm 0.018$ \\
C6 & $0.054 \pm 0.001$ & $0.139 \pm 0.005$ \\
HP14 & $0.227 \pm 0.012$ & $0.320 \pm 0.004$ \\
C14 & $0.130 \pm 0.002$ & $0.281 \pm 0.008$ \\
HP21 & $0.050 \pm 0.002$ & $0.184 \pm 0.014$ \\
C21 & $0.064 \pm 0.004$ & $0.166 \pm 0.004$
\end{tabular}

\footnotetext{
${ }^{a}$ Relative quantum yields were determined using 2-AP under identical solution conditions at $25^{\circ} \mathrm{C}$ as a ratiometric reference. Each value represents the mean \pm SD for three independent samples.

${ }^{b}$ Native conditions are defined as $50 \mathrm{mM} \mathrm{KOAc,} 5 \mathrm{mM} \mathrm{Mg}(\mathrm{OAc})_{2}, 10 \mathrm{mM}$ KHEPES (pH 7.4).

${ }^{c}$ Denaturing conditions are defined as $9 \mathrm{M}$ urea, $10 \mathrm{mM}$ KHEPES (pH 7.4).
} 


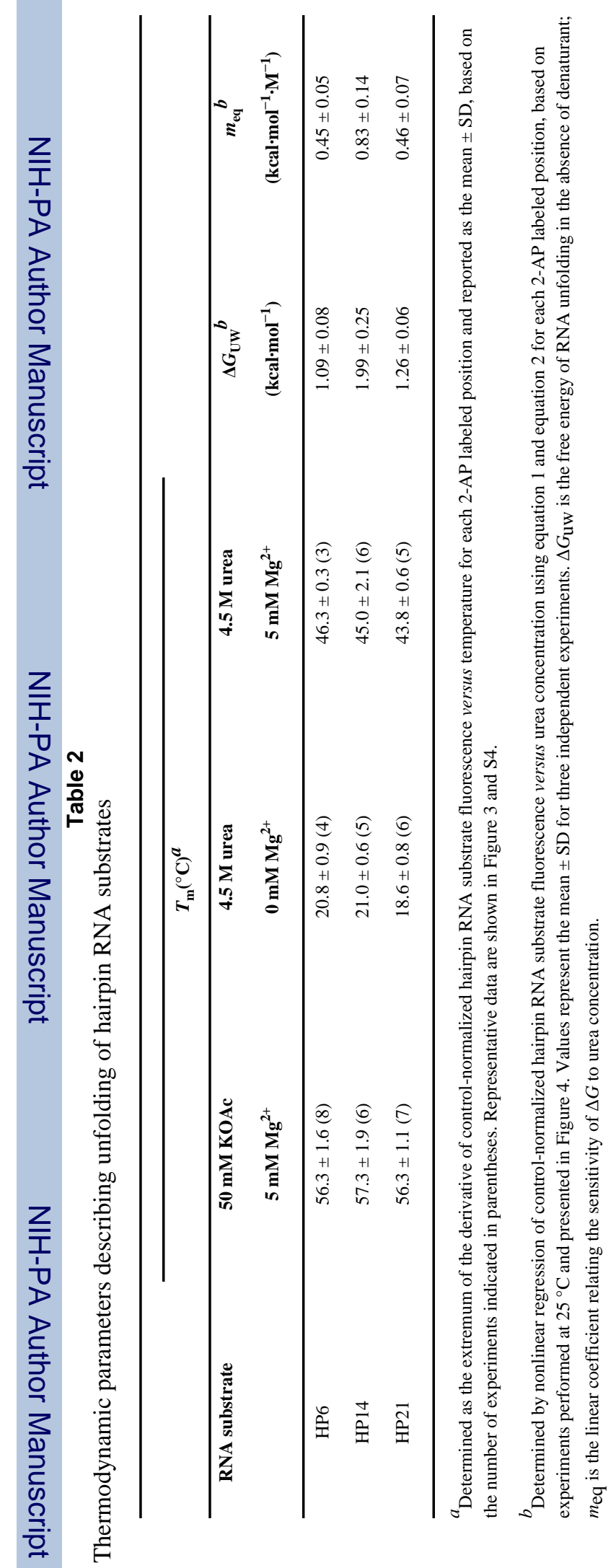




\section{Table 3}

$\mathrm{Mg}^{2+}$-dependence of hairpin RNA substrate folding

\begin{tabular}{ccc}
\hline RNA substrate & {$\left[\mathbf{M g}^{2+}\right]_{\mathbf{1} / 2}(\mu \mathrm{M})$} & $\boldsymbol{h}^{\boldsymbol{a}}$ \\
\hline HP6 & $35 \pm 4$ & $1.21 \pm 0.11$ \\
HP14 & $82 \pm 10$ & $1.15 \pm 0.17$ \\
HP21 & $68 \pm 4$ & $1.16 \pm 0.05$ \\
\hline
\end{tabular}

${ }^{a}$ Determined by nonlinear regression of hairpin RNA substrate fluorescence versus $\mathrm{Mg}^{2+}$ concentration at $25^{\circ} \mathrm{C}$ using equation 3 . Values are quoted as the mean \pm SD for five independent experiments. 
Ballin et al.

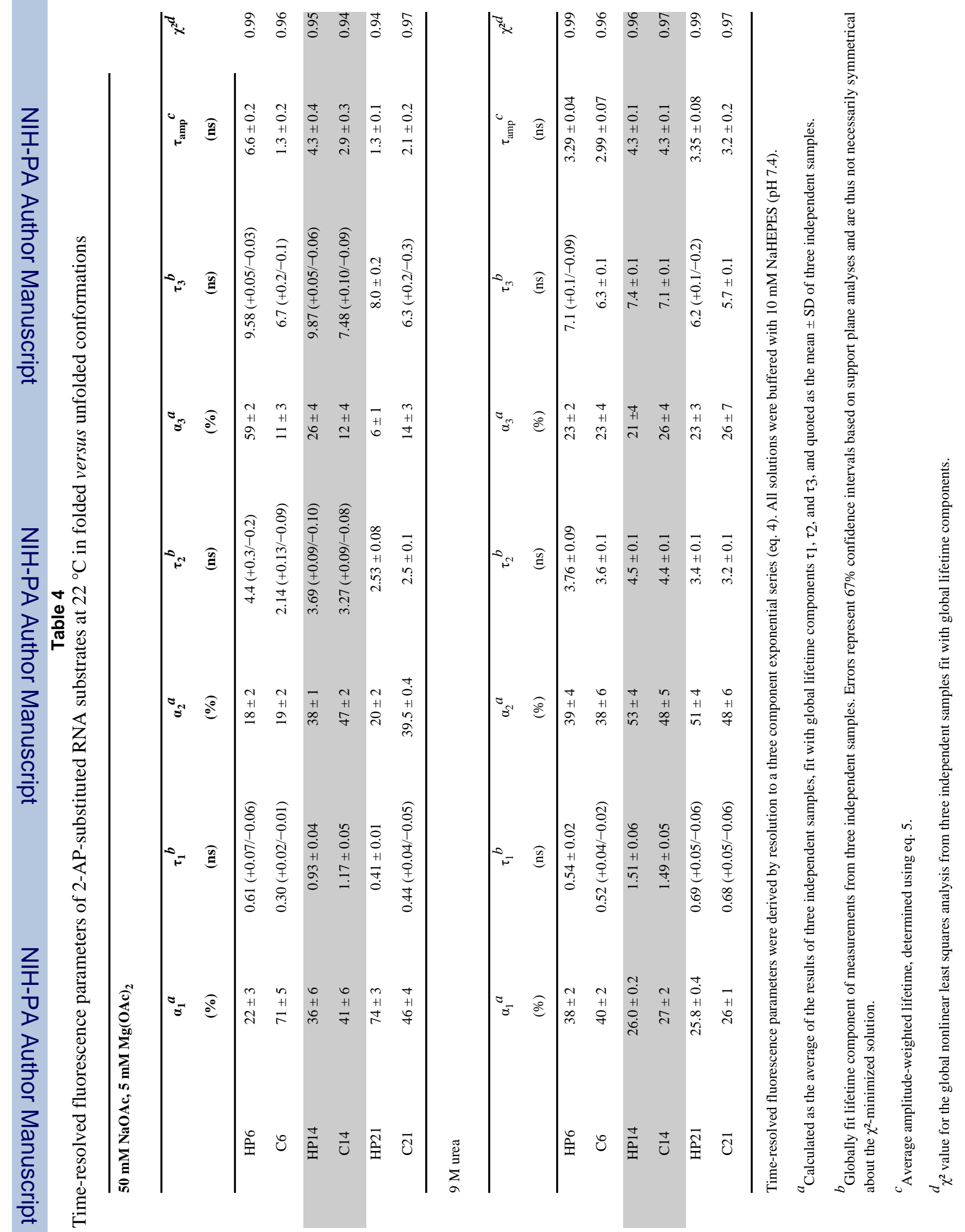

